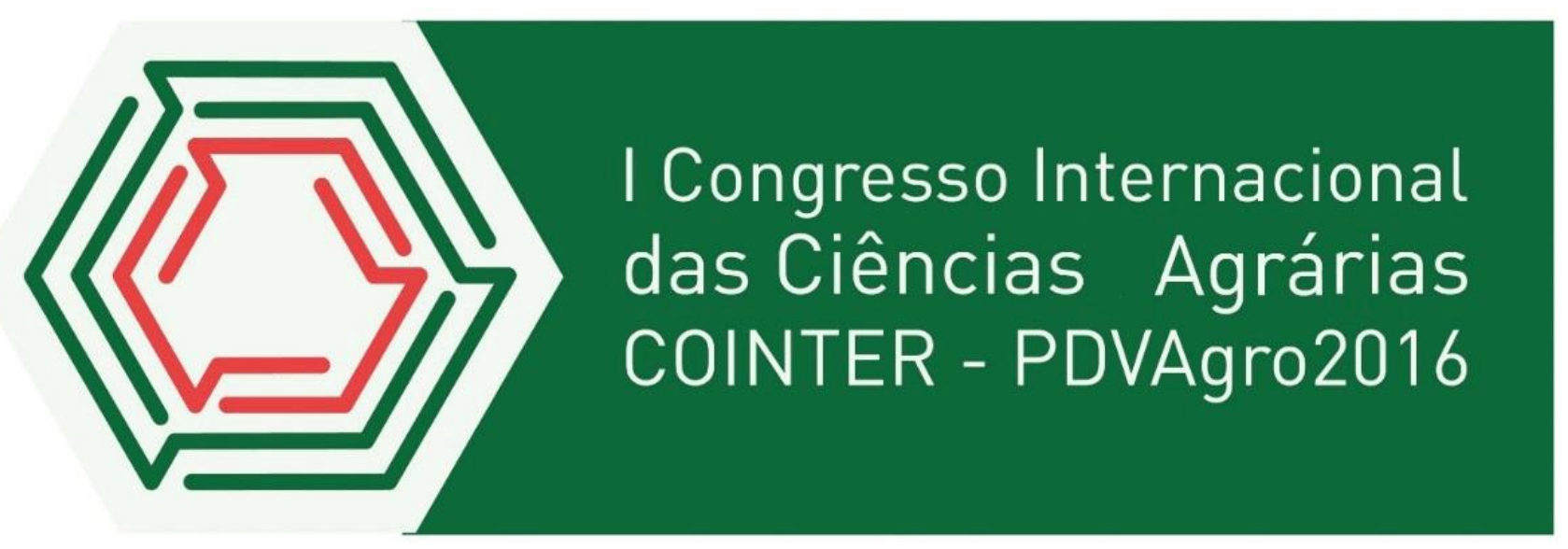

\title{
AVALIAÇÃO MICROBIOLÓGICA DO QUEIJO DE MANTEIGA COMERCIALIZADO NA FEIRA LIVRE DO MUNICÍPIO DE SOLÂNEA-PB
}

\author{
Apresentação: Pôster
}

\begin{abstract}
Alcimar de Melo Diasi; Vanessa Ribeiro de Lima Fidelis²; Viviane de Oliveira Andrade ${ }^{3}$; Emmanuel Moreira Pereira ${ }^{3}$, Welliton Barros de Magalhães ${ }^{4}$
\end{abstract}

\section{Introdução}

O leite tem sido considerado como o alimento humano, mais próximo da perfeição, sendo de excepcional valor nutritivo devido aos carboidratos, proteínas, gorduras, sais minerais. É também meio nutritivo para o crescimento de muitos microrganismos. Um de seus derivados, o queijo para ser preparado vai depender da atividade de vários microrganismos, sendo que grandes variedades de queijos são preparadas a partir do mesmo lote de leite (ABREU,2011). Segundo Bortoleto et al., (1997) o queijo é o derivado mais tradicional derivado do leite.

Cerca de $50 \%$ de sua fabricação no Brasil ainda é feita artesanalmente e sem controle higiênico, sanitário ou de qualidade. Os vários processos de fabricação do queijo são apenas métodos diversificados de transformar grande parte dos componentes do leite em um produto de fácil conservação, grande valor nutritivo, sabores agradáveis e fácil digestão (DAVIS, 1963, citado por GONDIM). Segundo Munk \& Campos (1984), o queijo de manteiga é obtido da fusão da manteiga com coalhada de leite integral ou desnatado de formato quadrangular.

O queijo de manteiga, também conhecido como requeijão do sertão, requeijão do nordeste e requeijão do norte, possui origem brasileira, de grande aceitação nas regiões Norte e Nordeste do Brasil. Este tem sido uma das opções mais utilizadas para aproveitamento de leite nas fazendas situadas longe dos centros consumidores e laticínios. É um produto que apresenta fabricação simples e valor nutritivo indiscutível (CAVALCANTE E COSTA, 2005).

\footnotetext{
1 Aluno do curso Bacharelado em agroindústria, UFPB E-mail: alcymardias@ gmail.com

2 Aluno do curso Bacharelado em agroindústria, UFPB E-mail: vribeiro_ribeiro@hotmail.com

3 Aluno do curso Bacharelado em agroindústria, UFPB E-mail: vivianeoliverandrade@gmail.com

4 Doutorando, Departamento de Agricultura, Universidade Federal da Paraíba, CCHSA, emmanuel16mop@hotmail.com

5 Orientador/Técnico administrativo - UFPB/CCCHSA - Universidade Federal da Paraíba, e-mail: welliton.barros@ufv.br.
} 
Com isso o objetivo do presente trabalho foi analisar a vida de prateleira em temperatura ambiente do queijo de manteiga.

\section{Fundamentação Teórica}

O leite é um produto secretado das glândulas mamárias (úbere) e alimento indispensável aos mamíferos nos primeiros meses de vida. Quando obtido de maneira adequada, é uma emulsão de cor branca, ligeiramente amarelada, de odor suave e gosto adocicado (MACEDO; MESQUITA FILHO; LIMA, 2003).

Os vários estágios da cadeia de produção de leite, desde a vaca até o consumo, devem ser bem controlados, de maneira a assegurar qualidade e segurança do leite e seus derivados. É proibida pela legislação brasileira, segundo o RIISPOA (BRASIL, 1952) e a IN 51 (BRASIL, 2002), a comercialização de leite cru e de derivados produzidos com leite não pasteurizado.

Tratando-se da presença de microrganismos patogênicos em leite não-pasteurizado ou em queijos frescos elaborados com leite cru o risco para a saúde humana é significante se estes forem consumidos. Uma grave doença que pode ser ocasionada pelo consumo de leite e de algum tipo de queijo fresco é conhecida como listeriose que é causada pela Listeria monocytogenes (PEREDA, 2005b). Pesquisa realizada por Feitosa et al. (2003), no Rio Grande do Norte, mostrou que queijos de manteiga, produzidos com leite cru apresentavam microrganismos patogênicos,como a Salmonella que seria eliminada durante o processo de pasteurização.

Em se tratando do queijo de manteiga, os ingredientes utilizados são fermento lático, cloreto de sódio, citrato de sódio e bicarbonato de sódio, além da manteiga do sertão, que é constituída basicamente de gordura. Pela legislação brasileira (BRASIL, 2001), entende-se por Queijo de Manteiga: o produto obtido mediante coagulação do leite com emprego de ácidos orgânicos de grau alimentício, cuja massa é submetida à dessoragem, lavagem e fusão, com acréscimo exclusivamente de manteiga de garrafa ou manteiga da terra ou manteiga do sertão. Este é um queijo com teor de gordura nos sólidos totais variando entre $25 \%$ e $55 \%$, devendo apresentar um teor máximo de umidade de $54,9 \% \mathrm{~m} / \mathrm{m}$.

\section{Metodologia}

\section{Local do trabalho}


As análises microbiológicas foram realizadas no laboratório de microbiologia de Alimentos no Centro de Ciências Humanas, Sociais e Agrárias (CCHSA) da Universidade Federal da Paraíba (UFPB), Campus III - Bananeiras - PB, onde as amostras coletadas foram analisadas individualmente.

\section{Coleta da amostra}

O queijo de manteiga foi coletado na feira livre do município de Solânea-PB, onde o mesmo é comercializado. O queijo com peso de aproximadamente $1 \mathrm{~kg}$ dividido em $100 \mathrm{~g}$ e embalados a vácuo formando assim 6 amostras de queijo de manteiga. Foram realizados as analise microbiológica durante os meses de outubro a dezembro de 2015.

\section{Analise Microbiológica:}

As avaliações microbiológicas foram realizadas no Laboratório de Microbiologia de Alimentos pertencente à CCHSA/UFPB, conforme a metodologia descrita por Brasil (2001) instrução normativa $\mathrm{RDC}^{\mathrm{o}} 12$, de 2 de janeiro de 2001. Seguindo as seguintes analises:

- Detecção de Salmonellasp;

- Enriquecimento Seletivo;

- Plaqueamento Seletivo Diferencial;

- Confirmação Preliminar das Colônias Típicas de Salmonellasp;

- Coliformes Totais e Termotolerantes;

- Contagem de Staphylococcus aureus;

- Contagem total de bactérias aeróbias mesófilas e fungos filamentosos e não filamentosos;

\section{Resultados e Discussões}

\begin{tabular}{|c|c|c|c|c|c|c|}
\hline \multirow[t]{2}{*}{ MICRO-RGANISMOS } & \multicolumn{6}{|c|}{ PERÍODOS } \\
\hline & 0 & 1 & 2 & 3 & 4 & 5 \\
\hline $\begin{array}{l}\text { Coliformes totais (NMP/g) } \\
\text { Coliformes termotolerantes }\end{array}$ & $2,9 \times 10^{1}$ & Ausência & $4,6 \times 10^{1}$ & $7,4 \times 10^{1}$ & Ausência & Ausência \\
\hline $\begin{array}{l}\text { (NMP/g) } \\
\text { Staphylococcus aureus } \\
\text { Fungos filamentosos e não }\end{array}$ & $\begin{array}{l}\text { Ausência } \\
\text { Ausência }\end{array}$ & - Ausência & $\begin{array}{l}\text { Ausência } \\
\text { Ausência } \\
4\end{array}$ & $\begin{array}{r}\text { Ausência } \\
\text { Ausência } \\
4\end{array}$ & $\begin{array}{l}\text { Ausência } \\
\text { Ausência }\end{array}$ & $\begin{array}{c}\text { Ausência } \\
\text { Ausência } \\
4\end{array}$ \\
\hline filamentosos (UFC/g) & $1,5 \times 10^{2}$ & $2,35 \times 10$ & $137 \times 10$ & $149 \times 10$ & $372 \times 10^{3}$ & $5,4 \times 10$ \\
\hline $\begin{array}{l}\text { Bactérias Mesófilas (UFC/g) } \\
\text { Salmonela }\end{array}$ & $\begin{array}{l}>300 \\
\text { Ausência }\end{array}$ & $\begin{array}{l}6 \times 10^{5} \\
\text { Ausência }\end{array}$ & $\begin{array}{l}>300 \\
\text { Ausência }\end{array}$ & $\begin{array}{l}>300 \\
\text { Ausência }\end{array}$ & $\begin{array}{l}3,3 \times 10^{5} \\
\text { Ausência }\end{array}$ & $\begin{array}{l}180 \times 10^{5} \\
\text { Ausência }\end{array}$ \\
\hline
\end{tabular}

Tabela. Contagem Microbiana em amostras do queijo de manteiga durante o armazenamento.

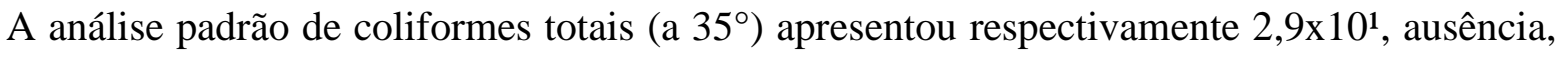
4,6x $10^{1}, 7,4$ e ausências nos períodos 4 e 5 . A análise de coliforme termotolerantes $\left(\mathrm{a} 45^{\circ}\right)$ apresentou ausências em todos os períodos. A análise de Staphylococcus aureus também não apresentou incidência, portanto a análise deu negativo. A análise de fungos filamentosos e não filamentosos variou entre $1,5 \times 10^{2}$ à $5,4 \times 10^{4} \mathrm{~A}$ análise de bactérias mesófilas variou de $>300$ à 
180x105. A Resolução - RDC n 12/2001 (BRASIL, 2001) não estabelece limites para as contagens de bactérias aeróbias mesófilas e bolores e leveduras em queijo manteiga, porém os valores encontrados podem ser considerados elevados;

Aycicek; Oguz; Karci (2006) consideram que a contagem em placas de bactérias aeróbias mesófilas é um dos indicadores microbiológicos para a qualidade do alimento. Os bolores e leveduras nas amostras analisadas foram considerados elevados para esse produto, os coliformes a $45{ }^{\circ} \mathrm{C}$ não foram detectados em nenhuma das amostras estando de acordo com a Resolução - RDC n ${ }^{0}$ 12/2001 (BRASIL, 2001).

Os coliformes são um grupo de bactérias, sendo a mais importante a Escherichia coli, que demonstram uma possível contaminação do alimento por material fecal, oriunda da higiene deficiente (SUGAR, 2007). A presença de Coliformes totais $\left(\mathrm{a} 35^{\circ} \mathrm{C}\right.$ ) e de coliformes fecais (a $45^{\circ} \mathrm{C}$ ) em alimentos processados segundo Silva (1997) é considerada uma indicação útil de contaminação póssanitização ou pós-processo, evidentemente práticas de higiene e sanificação aquém dos padrões requeridos para o processamento de alimentos (GEUS; LIMA, 2006).

Staphylococcus coagulase positiva (Staphylococcus aureus) são causadores de toxinfecção alimentar, e não houve a incidência. Para proteger a saúde da população a legislação estabelece como padrão o máximo de $1 \times 10^{3}$ unidades formadoras de colônia (UFC) - (BRASIL, 2001). A analise para presença de salmonela houve ausência em todos os períodos.

\section{Conclusões}

O queijo de manteiga apresentou condições higiênicas satisfatórias, pois apresentou baixa contagem de mesófilos, coliformes totais, coliformes termotolerantes houve ausência, Staphylococcus coagulase positiva (S. aureus) e não houve incidência de salmonela. Portanto o queijo de manteiga analisado estaria apto para consumo. As analises microbiológicas tiverem também o intuito de analisar a vida de prateleira em temperatura ambiente.

\section{Referências}

ABREU, Abiah Narumi Ido de. Contagem microbiana e incidência de aflatoxina M1 em queijo ralado e requeijão, comercializados em diferentes cidades do Estado de Minas Gerais. 2011.

AYCICEK, Hasan; OGUZ, Utku; KARCI, Koray. Comparison of results of ATP bioluminescence and traditional hygiene swabbing methods for the determination of surface cleanliness at a hospital 
kitchen. International journal of hygiene and environmental health, v. 209, n. 2, p. 203-206, 2006.

BRASIL, Ministério Agricultura, Pecuária e Abastecimento. Decreto n³0691, de 29 de março de 1952. Brasília: Diário Oficial da União, 1952.

BRASIL, Ministério Agricultura, Pecuária e Abastecimento. Instrução Normativa no 51 , de 18 de setembro de 2002. Brasília: Diário Oficial da União, 2002.

BRASIL, Ministério Agricultura, Pecuária e Abastecimento. Instrução Normativa n⿳0 30, de 26 de junho de 2001. Brasília: Diário Oficial da União, 2001.

BRASIL. Ministério da Saúde. Agência Nacional de Vigilância Sanitária. Resolução - RDC nº 12, de 2 de janeiro de 2001. Dispõe sobre Regulamento Técnico sobre Padrões Microbiológicos para Alimentos. Brasília: Diário Oficial da União, jan. 2001.

BORTOLETO, Eloisa E. et al. Leite: realidade e perspectivas. SAA, 1997.

CAVAlCANTE, A. B. D.; COSTA, J. M. C. Padronização da Tecnologia de Fabricação do Queijo de Manteiga. Revista Ciência Agronômica. v. 36, n. 2, p. 215-220, mai/ago. 2005.

DAVIS, B. K. Studies on the termination of pregnancy with norethynodrel.Journal of Endocrinology, v. 27, n. 1, p. 99-106, 1963.

FEITOSA, T. BORGES, M. F. NASSU, R. T. AZEVEDO, E. H. F. MUNIZ, C. R. Pesquisa de Salmonella sp., Listeria sp. e microrganismos indicadores higiênico-sanitários em queijos produzidos no Estado do Rio Grande do Norte. Ciência e Tecnologia dos Alimentos, Campinas, v. 23 (Supl): p.162-165, dez. 2003.

GEUS, JAM; LIMA, I. A. Análise de coliformes totais e fecais: Um Comparativo entre técnicas oficiais VRBA e Petrifilm EC aplicados em uma indústria de carnes. Anais do II Encontro de Engenharia e Tecnologia dos Campos Gerais, 2006.

PEREDA, J. A. O. (org.). Tecnologia de Alimentos. Porto Alegre: Artmed, 2005a.

SILVA JÚNIOR, Aluísio Gomes Da. Modelos tecnoassistenciais em saúde: o debate no campo da saúde coletiva. In: Saúde em Debate. Hucitec, 1997.

SUGAR, MICROBIOLOGICAL CONDITIONS OF COMMERCIALIZED. Condições Microbiológicas de Caldos de Cana Comercializados em Umuarama (PR). Revista Brasileira de Tecnologia, v. 1, n. 02, p. 61-69, 2007. 